\title{
(2) OPEN ACCESS \\ Placental polyp with arteriovenous malformation treated with a gonadotoropin-releasing hormone antagonist
}

\author{
Mayuko Goda (1) , Takashi Suzuki, Hiroshi Adachi
}

Obstetrics and gynaecology, Seirei Hamamatsu Hospital, Hamamatsu, Shizuoka, Japan

\section{Correspondence to} Dr Mayuko Goda; m_beeta16@yahoo.co.jp

Accepted 24 August 2021

\section{Check for updates}

(c) BMJ Publishing Group Limited 2021. Re-use permitted under CC BY-NC. No commercial re-use. See rights and permissions. Published by BMJ.

To cite: Goda M, Suzuki T, Adachi H. BMJ Case

Rep 2021;14:e244664.

doi:10.1136/bcr-2021-

244664

\section{SUMMARY}

A 35-year-old woman (gravida 1, para 0) underwent termination of pregnancy (ToP) at 12 weeks of gestation. One month after ToP, she experienced significant vaginal bleeding and the mass with blood flow was identified on imaging. The presence of a placental polyp with arteriovenous malformation (AVM) was suspected on transvaginal sonography and MRI. Since the bleeding had ceased when she visited our hospital, we decided to treat the placental polyp with AVM with gonadotropinreleasing hormone (GnRH) antagonist therapy instead of surgery. Two months after GnRH antagonist treatment, the mass and blood flow in the uterus disappeared. Menstruation resumed 1 month after the completion of treatment. In our case, we were able to successfully treat placental polyps with AVM using GnRH antagonist therapy.

\section{BACKGROUND}

A placental polyp with arteriovenous malformation (AVM) is a remnant piece of the placental tissue that remains in the uterine cavity after termination of pregnancy (ToP) or parturition. Placental polyps are seen in less than $0.25 \%$ of all pregnancies. ${ }^{1}$ Furthermore, only $6 \%$ of placental polyps are hypervascular and associated with severe haemorrhage. ${ }^{1}$ However, when presenting with severe vaginal bleeding, these disorders can be life-threatening. Recently, it has been suggested that these conditions may overlap in terms of their underlying pathophysiology. ${ }^{2}$ Some case reports suggested the coexistence of AVM with a retained product of conception (RPOC), which is finally diagnosed by pathology. ${ }^{3}$ It is difficult to differentiate placental polyp, RPOC or AVM by imaging alone. Therefore, in our case, we refer to this entity as a placental polyp with AVM throughout this article. When bleeding is acute and profuse, immediate intervention is required. These interventions include uterine artery embolisation (UAE), temporal iliac artery occlusion, hysteroscopy, hysterectomy and medications. However, in recent years, conservative treatment with hormone therapies such as a gonadotropin-releasing hormone $(\mathrm{GnRH})$ agonist with aromatase inhibitor has been reported to be effective for placental polyp with AVM. ${ }^{4}$ Since a GnRH antagonist has a mechanism nearly identical to that of a GnRH agonist, we treated our patient with it. Here, we report a case of a patient with placental polyp with AVM treated with a GnRH antagonist.

\section{CASE PRESENTATION}

A 35-year-old woman (gravida 1, para 0) had ToP at 12 weeks of gestation with gemeprost. Five weeks after ToP, she had significant vaginal bleeding and consulted her primary care doctor. The doctor found a mass with blood flow in the uterine cavity. Human chorionic gonadotropin (hCG) was also detected in her urine. The patient was referred to our hospital for further investigation and treatment.

\section{INVESTIGATIONS}

At the initial presentation, the patient's vital signs were normal. Speculum examination showed only brownish discharge with no active bleeding. Serum hCG level was $27 \mathrm{mIU} / \mathrm{mL}$. Transvaginal sonography (TVS) showed a hypoechoic region with arterial and venous flow that was $35 \mathrm{~mm}$ in diameter in the uterine cavity (figure $1 \mathrm{~A}$ and $\mathrm{B}$ ). Peak systolic velocity (PSV) of the vascular region was $>67 \mathrm{~cm} / \mathrm{s}$. The patient underwent contrastenhanced MRI of the pelvis. T2-weighted images showed a significant hypervascular lesion and signal void in the anterior wall of the uterus, which indicated a vascular structure continuous from the lesion to the myometrium and an abnormal blood vessel with the arterial component (figure $2 \mathrm{~A}$ and B). The presence of a placental polyp with AVM was suggested by colour Doppler ultrasound, MRI and hCG level. The haemoglobin ( $\mathrm{Hb})$ level was $106 \mathrm{~g} / \mathrm{L}$, and the patient did not have continuous bleeding.

\section{DIFFERENTIAL DIAGNOSIS}

Secondary postpartum haemorrhage is due to a placental polyp, hypervascular RPOC, uterine AVM or retained placenta accreta. ${ }^{1}$ In our case, colour Doppler imaging showed a hypervascular mass that extended to the myometrium and was suspicious for AVM. The TVS demonstrated a hypoechoic region and MRI showed a lowintensity region and signal void in the uterus, and the high hCG level ${ }^{1}$ led us to the diagnosis of the placental polyp with AVM.

\section{TREATMENT}

As the patient had desired to preserve her fertility, we decided to treat her with medication after explaining the risks and benefits of treatment with UAE, hysteroscopy and medications. We started treatment with $40 \mathrm{mg} /$ day of oral $\mathrm{GnRH}$ antagonist (relugolix). After 2 weeks of treatment, 


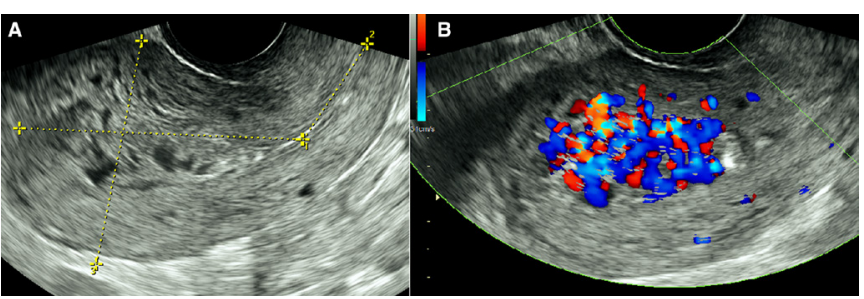

Figure 1 Images obtained using TVS before treatment. (A) Transvaginal ultrasonography shows a heterogeneous mass within the uterine cavity. (B) Colour Doppler ultrasonography shows that this mass has prominent arterial and venous flow. TVS, transvaginal sonography.

the patient presented to the emergency department with significant vaginal bleeding. TVS showed that the mass in the uterine cavity had reduced in size to $24 \mathrm{~mm} \times 18 \mathrm{~mm}$ in diameter, and PSV was reduced to $17 \mathrm{~cm} / \mathrm{s}$ (table 1 ). Contrastenhanced CT showed arterial blood flow in the uterine cavity (figure 3), which was considered to be the site where the bleeding originated. Her $\mathrm{Hb}$ level was $103 \mathrm{~g} / \mathrm{L}$, and due to the low fibrinogen level of $187 \mathrm{mg} / \mathrm{dL}$, four units of fresh frozen plasma were transfused. The patient's condition was stable, and vaginal bleeding had stopped. We continued to treat the patient with medication.

\section{OUTCOME AND FOLLOW-UP}

In our patient, the placental polyp with AVM reduced in size from $35 \mathrm{~mm}$ to $24 \mathrm{~mm}$ after 3 weeks of GnRH antagonist therapy and completely disappeared after 6 weeks of treatment, as confirmed by TVS (figure 4). Treatment was thus stopped. Ten weeks from the start of therapy ( 1 month after the final administration of GnRH antagonist), her menstruation resumed with a regular cycle.

\section{DISCUSSION}

In the present case, we successfully treated a placental polyp with AVM using a GnRH antagonist. UAE, temporal iliac artery occlusion, hysteroscopy, hysterectomy and medications are used to treat placental polyps with $\mathrm{AVM}^{4}$; the chosen treatment depends on whether the bleeding is continuous and the blood flow velocity is high within the polyp. Timor-Tritsch et al reported that UAE may be considered when the velocity is $>60-70 \mathrm{~cm} / \mathrm{s} .{ }^{6}$ Timmerman et al showed that UAE was required if the PSV was $>87 \mathrm{~cm} / \mathrm{s}$, and all AVMs with PSV $<39 \mathrm{~cm} / \mathrm{s}$ disappeared spontaneously without embolisation. ${ }^{7}$ Treatment with UAE can preserve the uterus, but even temporary embolisation results in uterine ischaemia, which increase the risk of total hysterectomy

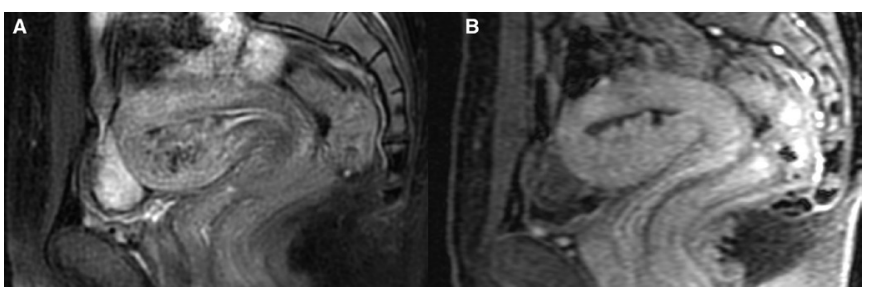

Figure 2 (A) T2-weighted MRI. The uterine placental polyp with AVM was determined to be a low-intensity lesion. The placental polyp with AVM was associated with a signal void. (B) T1-weighted LAVA. There is significant staining in the placental polyp. AVM, arteriovenous malformation; LAVA, liver acquisition with volume acceleration.
Table 1 Sonographic findings of intrauterine mass and uterine arteries

\begin{tabular}{lllll}
\hline $\begin{array}{l}\text { Time after } \\
\text { treatment }\end{array}$ & $\begin{array}{l}\text { Size of } \\
\text { intrauterine } \\
\text { mass }(\mathrm{mm})\end{array}$ & $\begin{array}{l}\text { PSV of } \\
\text { intrauterine } \\
\text { mass }(\mathrm{cm} / \mathrm{s})\end{array}$ & $\begin{array}{l}\text { PSV of right } \\
\text { UA }(\mathrm{cm} / \mathrm{s})\end{array}$ & $\begin{array}{l}\text { PSV of left UA } \\
(\mathrm{cm} / \mathrm{s})\end{array}$ \\
\hline Before treatment & $35 \times 24$ & 67 & 52.8 & 62.4 \\
\hline 5 days & $30 \times 16$ & 90 & 75.8 & 57.8 \\
\hline weeks & $24 \times 18$ & 16.8 & 41.8 & 33.2 \\
\hline 6 weeks & None & n.a. & 41.9 & 37 \\
\hline 10 weeks & None & n.a. & 36.3 & 27.5 \\
\hline 14 weeks & None & n.a. & 31.8 & 39.1 \\
\hline
\end{tabular}

n.a., not assessed; PSV, peak systolic velocity; UA, uterine artery.

due to infection, ${ }^{8}$ Asherman's syndrome, ${ }^{9}$ shortened cervix and placenta accreta. ${ }^{10}$ Therefore, conservative treatment is recommended for women who wish to preserve fertility. Our patient did not have continuous vaginal bleeding, but the PSV was $70-90 \mathrm{~cm} / \mathrm{s}$; thus, we opted for treatment with medication to preserve her fertility.

Regarding treatment, the utility of GnRH antagonists, aromatase inhibitors and tranexamic acid have been reported. ${ }^{4}$ There have been reports of successful treatment of placental polyps with AVM using a GnRH agonist, ${ }^{41}$ but not using an antagonist.

The mechanism of GnRH agonist activity in treating a placental polyp with AVM is not known. GnRH agonists suppress gonadal steroidogenesis by downregulating and desensitising $\mathrm{GnRH}$ receptors, thereby inhibiting the production of luteinising hormone and follicle-stimulating hormone and resulting in a profound hypo-oestrogenic state. This hypo-oestrogenicity reduces uterine arterial blood flow and induces uterine atrophy. This may cause mechanical compression or constriction and clotting of the AVM, thus leading to its resolution. ${ }^{4}$ However, a GnRH agonist is administered with an aromatase inhibitor, which suppresses the initial oestrogen surge induced by the GnRH agonist. Increases in oestradiol levels occur in approximately $40 \%$ of patients treated with GnRH agonists. ${ }^{12}$ Therefore, a $\mathrm{GnRH}$ antagonist may be superior to a $\mathrm{GnRH}$ agonist in that it does not cause an oestrogen surge and maintains a low-oestrogen state from the beginning of administration.

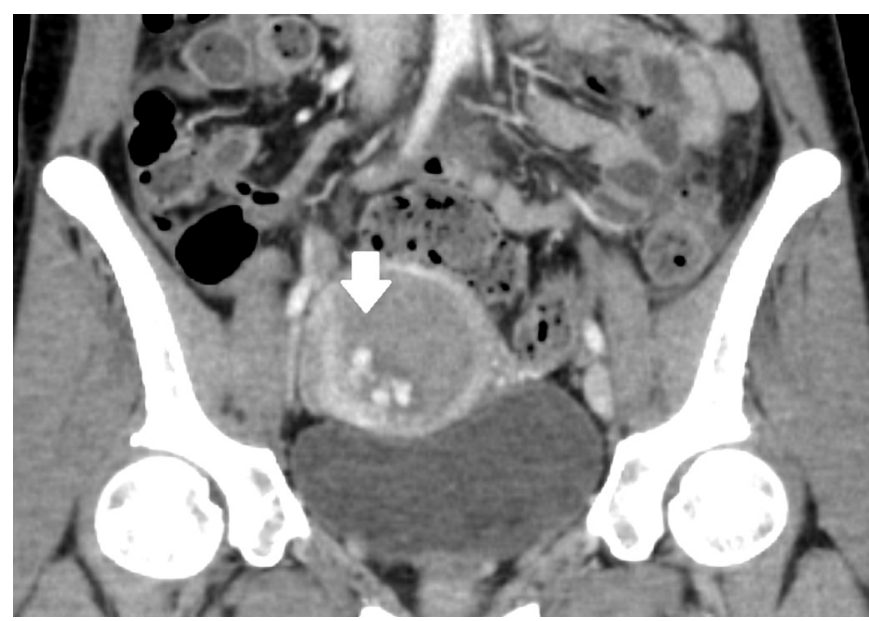

Figure 3 CECT revealed the enhanced lesion within the uterus, which indicates hypervascularity of the mass from the uterine artery. CECT, contrast-enhanced CT. 


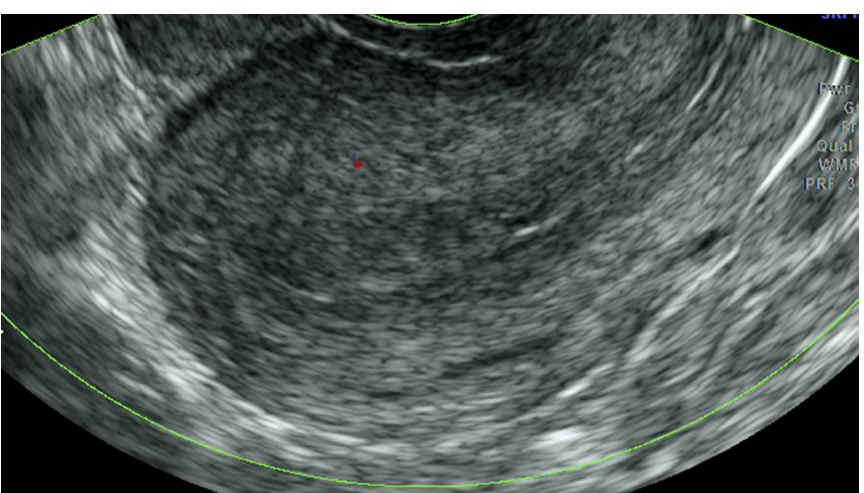

Figure 4 Images obtained with TVS after 6 weeks. The placental polyp with AVM had completely resolved after 6 weeks of GnRH antagonist therapy. AVM, arteriovenous malformation; $\mathrm{GnRH}$, gonadotropinreleasing hormone; TVS, transvaginal sonography.

Osuga et al reported that in patients treated with a $\mathrm{GnRH}$ antagonist, the median oestrogen level decreased from baseline to below postmenopausal levels in 2 weeks, whereas when administering a GnRH agonist, this change required 4 weeks. $^{12}$ In addition, compared with a GnRH agonist, treatment with a GnRH antagonist is associated with faster recovery of the menstrual cycle after the discontinuation of treatment (median time with relugolix, 37 days; median time with leuprorelin, 65 days), which may be important for women who wish to become pregnant sooner. For the above reasons, we believe that a $\mathrm{GnRH}$ antagonist may be more suitable than a GnRH agonist for the treatment of a placental polyp with AVM.

We observed that GnRH antagonist treatment decreased the PSV of the AVM and uterine arteries. Spong et al reported that Doppler studies demonstrated a reduction in uterine artery blood flow by approximately 25\% after GnRH agonist therapy. ${ }^{13}$ Arteries contain oestrogen and progesterone receptors; oestrogen is an arterial vasodilator, and it also inhibits contractility of intramyometrial arteries. These findings imply that the diminished myometrial arterial system may also be a direct effect of the hypo-oestrogenic state. In the present case, we assumed that the GnRH antagonist also decreased the blood flow and reduced the size of the uterine mass.

Regarding the time from diagnosis to resolution, Mori et al reported a duration of 4-21 weeks, ${ }^{14}$ and Timor-Tritsch et al reported a duration of 2-8 weeks in patients treated expectantly. ${ }^{6}$ Because the velocity of blood flow in the mass was not high, these patients could be managed expectantly. In addition, the time to resolution when treated with a $\mathrm{GnRH}$ agonist and aromatase inhibitor was 4-24 weeks, and it was 4-20 weeks when treated with a GnRH agonist alone. In the present case, the PSV of the intrauterine AVM was rapid, suggesting that treatment with UAE may have been considered. However, treatment with a GnRH antagonist resolved the mass completely after 6 weeks. Because the time to resolution varied in both the expectant management and $\mathrm{GnRH}$ agonist groups in the reports cited, it is difficult to compare them to this case. However, medical treatment was successful even with a high PSV, and only a single oral drug was required. These may be considered advantages of this treatment.

In this case, we discovered two important clinical issues. First, a GnRH antagonist was effective in treating a placental

\section{Patient's perspective}

This was my first pregnancy, but I had ToP. After that, I had vaginal bleeding and I was told that if it was life-threatening, I would have to have a UAE or hysterectomy in the worst case. I was very worried and sad to hear that. However, after about a month of relugolix, the bleeding and mass in the uterus disappeared. I was incredibly happy to hear that my uterus returned to its original state and I was able to conceive again.

\section{Learning points}

- Gonadotropin-releasing hormone (GnRH) antagonist may have a potential benefit as a medical treatment for placental polyp with arteriovenous malformation (AVM) compared with a GnRH agonist with an aromatase inhibitor.

- A GnRH antagonist may decrease the systolic velocity of uterine arteries and mass size in the uterine cavity. Surgical treatments are recommended if peak systolic velocity is high; however, a GnRH antagonist is considered to be effective.

- This is the first-ever reported case of a placental polyp with AVM treated with a GnRH antagonist.

polyp with AVM. Second, the treatment reduced blood flow velocity in both the AVM and the uterine arteries. To our knowledge, this is the first case of placental polyps with AVM treated with a GnRH antagonist.

Acknowledgements We would like to thank Editage (www.editage.com) for English language editing

Contributors MG, TS and HA were involved in study design and data interpretation. MG and TS were involved in the data analysis. All authors critically revised the report, commented on drafts of the manuscript and approved the final report.

Funding The authors have not declared a specific grant for this research from any funding agency in the public, commercial or not-for-profit sectors.

Competing interests None declared.

Patient consent for publication Obtained.

Provenance and peer review Not commissioned; externally peer reviewed.

Open access This is an open access article distributed in accordance with the Creative Commons Attribution Non Commercial (CC BY-NC 4.0) license, which permits others to distribute, remix, adapt, build upon this work non-commercially, and license their derivative works on different terms, provided the original work is properly cited and the use is non-commercial. See: http://creativecommons.org/ licenses/by-nc/4.0/.

\section{ORCID iD}

Mayuko Goda http://orcid.org/0000-0002-8727-8958

\section{REFERENCES}

1 Ishihara T, Kanasaki H, Oride A, et al. Differential diagnosis and management of placental polyp and uterine arteriovenous malformation: case reports and review of the literature. Womens Health 2016;12:538-43.

2 Kido A, Togashi K, Koyama T, et al. Retained products of conception masquerading as acquired arteriovenous malformation. J Comput Assist Tomogr 2003;27:88-92.

3 Goyal S, Goyal A, Mahajan S, et al. Acquired uterine arteriovenous malformation developing in retained products of conception: a diagnostic dilemma. J Obstet Gynaecol Res 2014;40:271-4.

4 Vilos AG, Oraif A, Machado M, et al. Resolution of uterine arteriovenous malformation and maintenance of reproduction in 20 women treated with a GnRH agonist concomitantly with an aromatase inhibitor and tranexamic acid. J Obstet Gynaecol Can 2019;41:772-81.

5 Marques K, Looney C, Hayslip C, et al. Modern management of hypervascular placental polypoid mass following spontaneous abortion: a case report and literature review. Am J Obstet Gynecol 2011;205:e9-11. 
6 Timor-Tritsch IE, Haynes MC, Monteagudo A, et al. Ultrasound diagnosis and management of acquired uterine enhanced myometrial vascularity/arteriovenous malformations. Am J Obstet Gynecol 2016;214:731.e1-731.e10.

7 Timmerman D, Van den Bosch T, Peeraer K, et al. Vascular malformations in the uterus: ultrasonographic diagnosis and conservative management. Eur J Obstet Gynecol Reprod Biol 2000;92:171-8.

8 Song D, Liu Y, Xiao Y, et al. A matched cohort study comparing the outcome of intrauterine adhesiolysis for Asherman's syndrome after uterine artery embolization or surgical trauma. J Minim Invasive Gynecol 2014;21:1022-8.

9 Kozinszky Z, Sand S, Kløw N-E, et al. Shortened cervix in the subsequent pregnancy after embolization for postpartum cervical hemorrhage. Case Rep Obstet Gynecol 2014; $2014: 607835$

10 Inoue S, Masuyama H, Hiramatsu Y, et al. Efficacy of transarterial embolisation in the management of post-partum haemorrhage and its impact on subsequent pregnancies. Aust N Z J Obstet Gynaecol 2014;54:541-5.
11 Nonaka T, Yahata T, Kashima K, et al. Resolution of uterine arteriovenous malformation and successful pregnancy after treatment with a gonadotropin-releasing hormone agonist. Obstet Gynecol 2011:117:AOG.0b013e3181f7381f:452-5.

12 Osuga Y, Enya K, Kudou K, et al. Oral gonadotropin-releasing hormone antagonist relugolix compared with leuprorelin injections for uterine leiomyomas: a randomized controlled trial. Obstet Gynecol 2019:133:AOG.0000000000003141:423-33.

13 Spong CY, Sinow R, Renslo R, et al. Induced hypoestrogenism increases the arterial resistance index of leiomyomata without affecting uterine or carotid arteries. J Assist Reprod Genet 1995;12:338-41.

14 Mori M, Iwase A, Osuka S, et al. Choosing the optimal therapeutic strategy for placental polyps using power Doppler color scoring: transarterial embolization followed by hysteroscopic resection or expectant management? Taiwan J Obstet Gynecol 2016:55:534-8.

Copyright 2021 BMJ Publishing Group. All rights reserved. For permission to reuse any of this content visit

https://www.bmj.com/company/products-services/rights-and-licensing/permissions/

BMJ Case Report Fellows may re-use this article for personal use and teaching without any further permission.

Become a Fellow of BMJ Case Reports today and you can:

Submit as many cases as you like

- Enjoy fast sympathetic peer review and rapid publication of accepted articles

- Access all the published articles

Re-use any of the published material for personal use and teaching without further permission

Customer Service

If you have any further queries about your subscription, please contact our customer services team on +44 (0) 2071111105 or via email at support@bmj.com.

Visit casereports.bmj.com for more articles like this and to become a Fellow 